\title{
Role of AMCase in the Allergic and Non Allergic Ocular Pathologies
}

\author{
Salvatore Musumeci \\ Department of Chemical Sciences, University of Catania and Institute of Biomolecular Chemistry, CNR, Catania, Italy \\ Email address: \\ smusumeci@tiscalinet.it \\ To cite this article: \\ Salvatore Musumeci. Role of AMCase in the Allergic and Non Allergic Ocular Pathologies. Clinical Medicine Research. \\ Vol. 4, No. 6, 2015, pp. 172-181. doi: 10.11648/j.cmr.20150406.12
}

\begin{abstract}
Chitin is abundant in the structural coatings of fungi, insects, and parasitic nematodes, but it is not produced in mammals. The host defense against chitin-containing pathogens include production of chitinases. An acidic mammalian chitinase (AMCase) is produced in human epithelial cells of lower airways and conjunctiva via a Th2-specific, IL-13dependent pathway and seems to be associated to asthma and allergic ocular pathologies. The role of AMCase in allergic disease is only at beginning and many issues open new possibilities for its control using specific inhibitors of AMCase activity or modulating its expression. In patients with vernal keratoconjunctivitis (VKC) and with season allergic conjunctivitis (SAC) the level of AMCase activity in the tears was found significantly elevated when compare to healthy controls and the highest levels were found in VKC. When RNA was extracted by conjunctival epithelial cells of these patients, the Real Time PCR measurement confirmed that the mRNA expression correlates with tear AMCase activity and the expression was significantly higher in VKC and SAC respectively. Also Receiver Operating Characteristic (ROC) analysis demonstrated that the sensitivity and specificity of AMCase measurement were $100 \%$ respectively, addressing the use of AMCase assay in the biochemical diagnosis of VKC and SAC. Recent studies in rabbit, where a reactive uveitis was induced by LPS injection in eye's anterior chamber, confirmed that increased AMCAse activity was measurable in tears and that epithelial cells of conjunctiva express specific mRNA. A well as it was previously demonstrated in experimental model of mouse asthma, the inflammatory reaction induced by LPS was controlled by the chitinase inhibitor and steroid, instilled at $3 \mathrm{hr}$ interval in conjunctival sacs. In dry eye, another pathologies where the role of innate immunity is sustained by AMCase secretion, an increased AMCase activity was documented and the specific mRNA expressed by epithelial conjunctival cells. In this pathology the eye inflammation can be ascribed to a common mechanism mediated by AMCase, via a Th 2 specific, IL-13 dependent way. In synthesis AMCase may be considered an important mediator in the pathogenesis of Th2 inflammation eye's diseases, suggesting its potential diagnostic and therapeutic utility.
\end{abstract}

Keywords: AMCase, Tears, Allergy, Dry Eye

\section{Introduction}

Chitin, the second most abundant polysaccharide in nature, is not expressed in mammalian systems, but it is found in the structural coatings of fungi [1], the exoskeleton of many arthropods [2] and parasitic nematodes [3]. These chitin coats provide protection for pathogens from harsh conditions inside the host. Chitinase production is also a common feature of anti parasite responses of lower life forms against chitin coating organisms. Paradoxically, although chitin and chitin synthase do not exist in mammals, members of glycosyl hydrolase (GH18) family, such as AMCase, chitotriosidase, YKL-40 and YKL-39, Ym1, oviduct-specific glycoprotein and stabilin-1-interacting chitinase like protein have recently been described [4]. Chitotriosidase and acidic mammalian chitinase (AMCase) posses chitinase enzymatic activity, whereas other mammilian chitinases do not possess this activity. AMCase is a $50 \mathrm{kDa}$ protein that contains a $30-\mathrm{kDa} \mathrm{N}$-terminal catalytic domain that can hydrolyse chitin. Characteristic of this chitinase is the resistance to acidic $\mathrm{pH}$, which distinguish AMCase from Chit, that has its optimum at pH 6 [5-6].

A role for AMCase in asthma pathophysiology has been suggested by Zhu et al. [7], following the demonstration that AMCase expression increased in the lungs of ovalbuminsensitized mice, that developed airway hyperresponsiveness, compared to control animals. In this asthma model, AMCase 
is expressed in both airway epithelial cells and alveolar macrophages. Elevated expression of AMCase was also observed in lung tissue of asthmatic patients, when compared to normal subjects. Furthermore, Zhu et al. [7] showed that AMCase does not directly induce Th2 cytokine response, but mediates the effector response of IL-13 (a cytokine produced by Th2 cells). In fact, IL-13 expression was required for induction of AMCase, since IL-13-expressing mice had much higher levels of AMCase expression (mRNA) in lung epithelial cells compared to control animals. The role of
AMCase in mediating the inflammatory response in asthma remains unclear. However, it seems that AMCase activity is required for the increased production of monocyte and macrophage chemo attractants MCP-1, MCP-2 and MIP-1 $\beta$, the eosinophil chemoattractants eotaxin and eotaxin 2 , and the neutrophil chemo attractant epithelial-derived neutrophilactivating protein 78 (ENA-78). Increased production of these chemoattractants would lead to the increase of inflammatory infiltrates observed in chronic asthma.

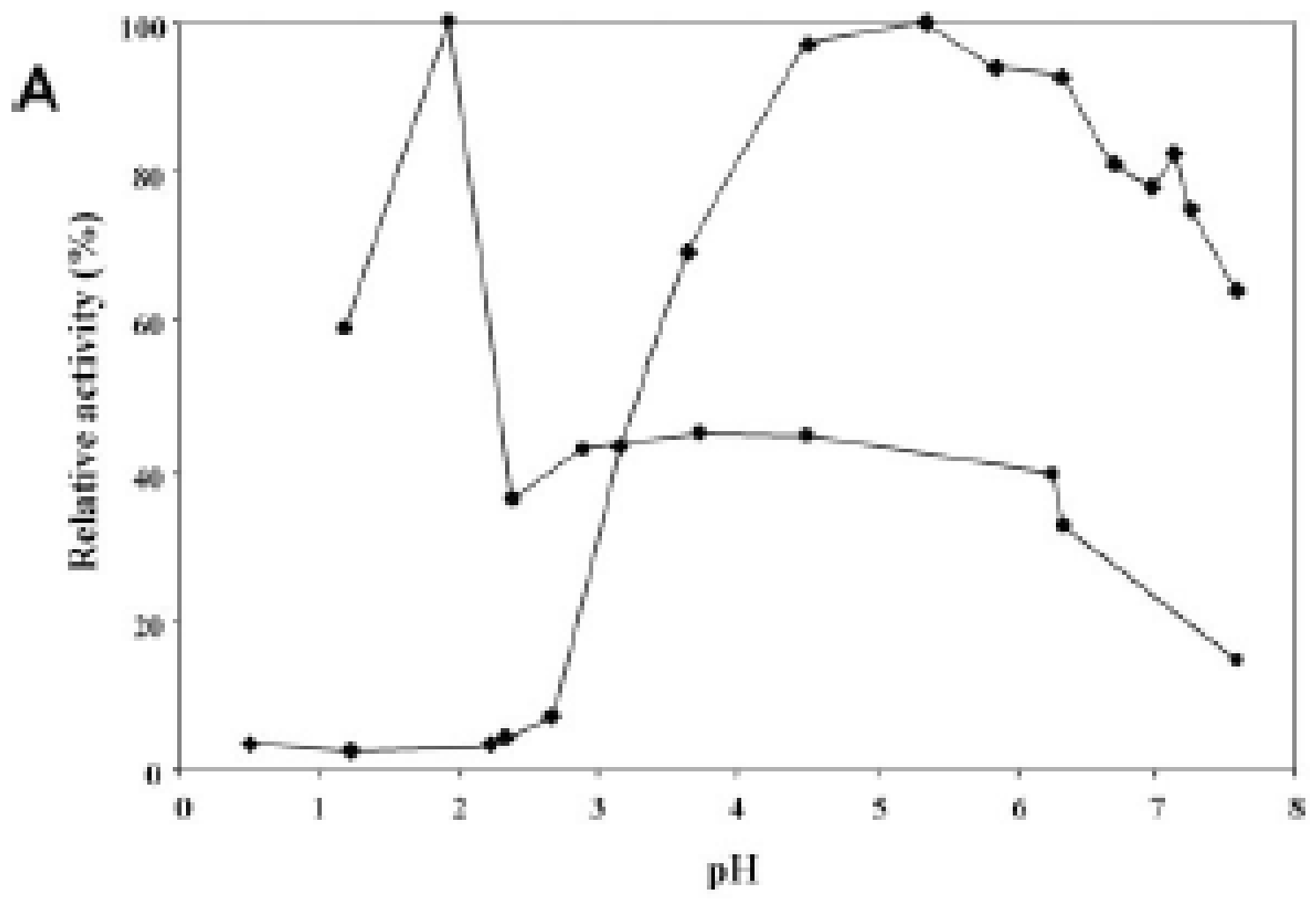

Figure 1. Relative activity (\%) of Chitotriosidase and AMCase at differerent pH values (from Boot et al 2001).

Interestingly, AMCase activity, suppresses the expression of the Th1 chemokines IP-10 and I-TAC, altering furtherly the immune balance in favour of a Th2 response [7]. Then AMCase posses the ability to exacerbate local inflammation by the activation of IL-13 pathway and facilitating the production of chemical mediators and it has been proposed as a potential therapeutic target in the Th2- mediated inflammation [8]. In fact, the inhibition of AMCase activity with the chitinase inhibitor allosamidin [9] or administration of antisera against AMCase, decreased the number of inflammatory cells in the bronchoalveolar lavage (BAL) fluid of ovalbumin-sensitized and challenged mice and reduced the asthma symptoms [7]. Interestingly, Ramanathan et al [10] showed that AMCase mRNA was significantly more expressed in nasal mucosa of patients with severe sinus inflammation than in control subjects. Clearly this finding does not mean that actually there are parasites containing chitin in the nose causing sinusitis, but rather support the concept that severe and persistent sinusitis may be a consequence of a misplaced immune response against parasites that are not really present. Also the IL-13, already known to be increased in asthmatics, was found to be higher in those with nasal polyposis, without any predictive values differently from AMCase [10].

The epithelial cells lining nasal and conjunctival surfaces play an important role as first responders of the immune system [10]. When they are distracted fighting non-existent parasites, they can produce chitinases, which represent a marker of innate immunity and of allergic response. More recently Chupp et al [11] found large quantity of YKL-40, a chitinase-like protein that lack enzymatic activity, in the serum and lungs of patients with severe asthma which correlate with the grade of the disease and represent a new marker of severity, supporting the previous observation of Zhu et al [7] in experimental asthma model. The role of AMCase in allergic diseases is suggestive of new possibilities for its control, using specific inhibitors of AMCase or modulating its expression. These observations allow us to hypothesize that AMCase could be also a potential key enzyme in the pathogenesis of allergic conjunctivitis (Figure 2). 


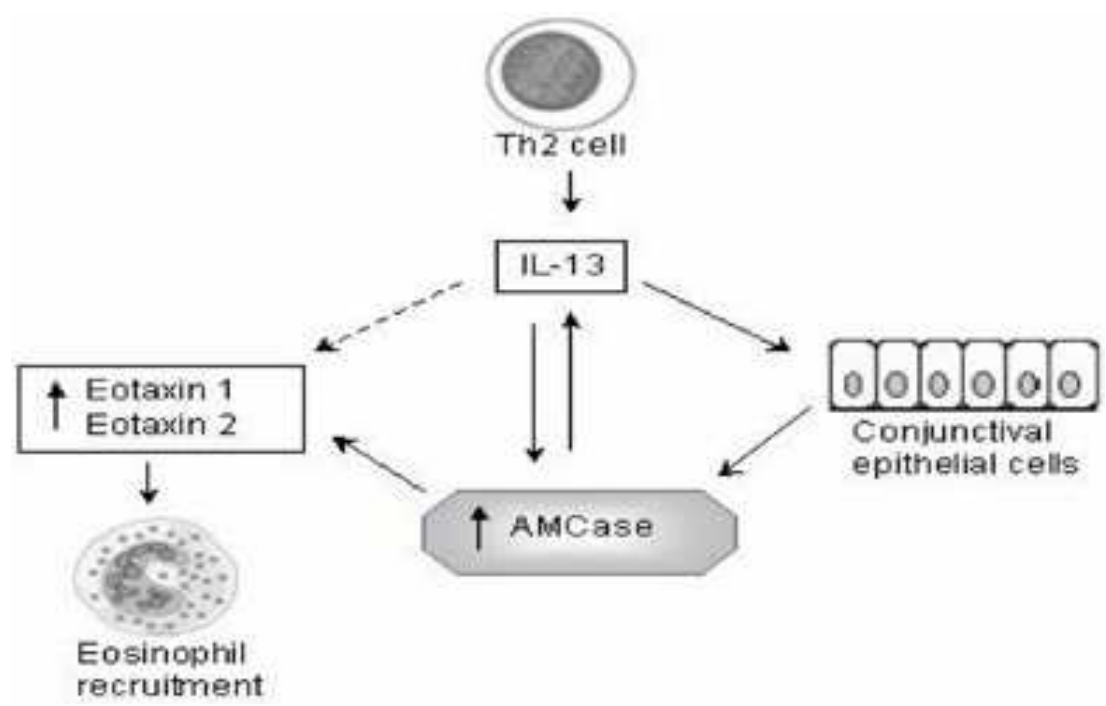

Figure 2. Model of AmCase control: Th2-driven allergic conjunctival response with IL-13 modulation of eotaxin 1-2 overexpression and eosinophil recruitment (From Musumeci et al 2008).

\section{Allergic Conjunctivitis}

Allergic conjunctivitis is very frequent and many eye doctors know seasonal allergic conjunctivitis (SAC) or vernal conjunctivitis (VKC) as the same entity- i.e., caused by an allergic reaction involving mast cell activation via $\operatorname{IgE}$. However VKC is more severe and often resistant to antiallergic and immunosuppressive treatment. $\mathrm{VKC}$ is a bilateral, recurrent inflammation of the conjunctiva that tends to occur in children. Its onset is in the spring and summer (i.e., vernal) - going into remission in the cooler months. There are 3 forms palphebral, limbal and mixed.
Both VKC and SAC are a Th2-driven disease with a Th2 cytokine derived pattern, with an overexpression of eotaxins, RANTES, MCP-1, MMPs [12, 13]. Moreover, Th2-associated cytokines and chemokines have been identified in the tears of patients with both VKC and season allergic conjunctivitis (SAC) [12, 13].

Our researches in VKC and SAC confirm the role of AMCase in human conjunctival allergic pathologies and the measurement of AMCase showed a sensitivity and specificity of $100 \%$ respectively, addressing the use of AMCase assay in the biochemical diagnosis of VKC and SAC (Figure 3) [14].

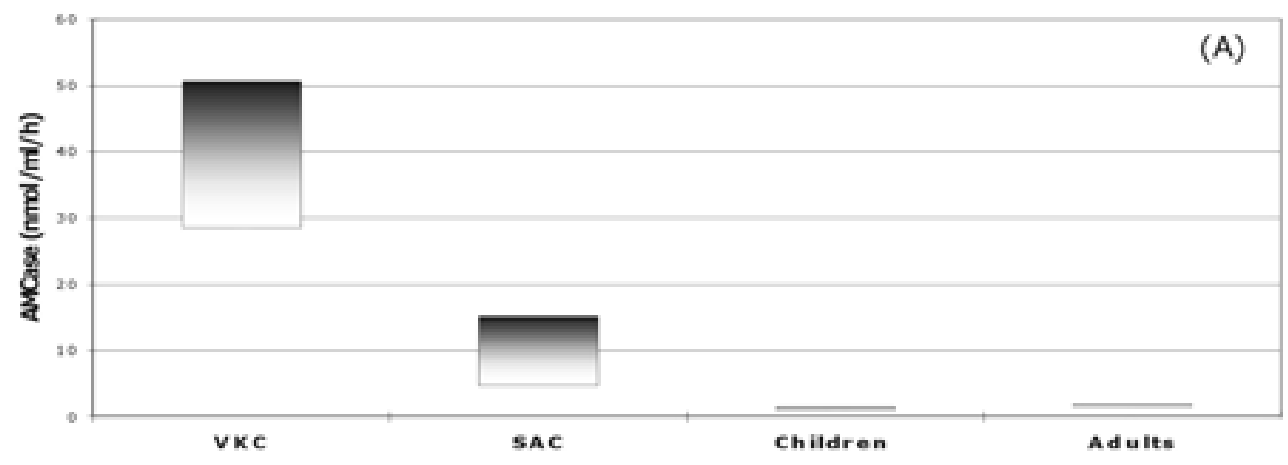

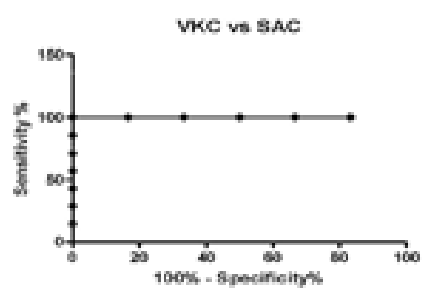

(B)

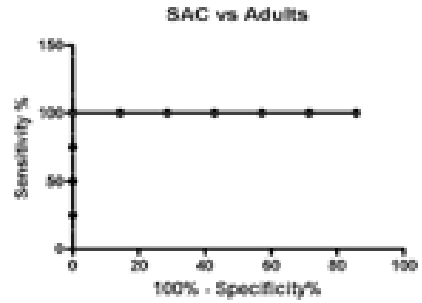

(C)

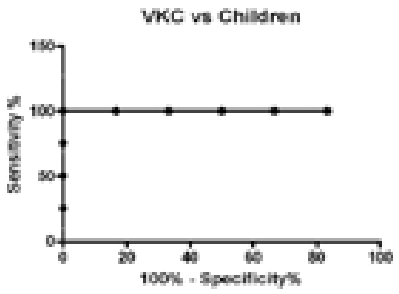

(D)

Figure 3. Distribution (panel A) and receiver-operator characteristic (ROC) analysis (panel B, C, D) of AMCase activities in VKC, SAC, adult and children controls (From Musumeci et al 2008). 
The activity of AMCase was significantly high in VKC and the exact nature of the chitinolytic activity in tears of allergic ocular pathologies was confirmed by the acid stability of this enzyme at $\mathrm{pH} \mathrm{2,} \mathrm{while} \mathrm{the} \mathrm{source} \mathrm{of}$ AMCAse from the conjunctival epithelial cells was

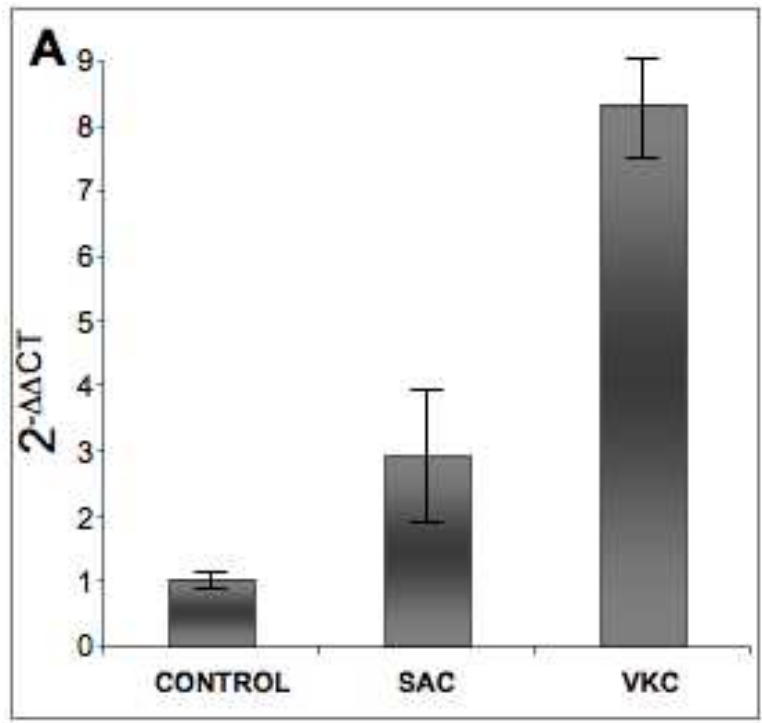

confirmed by RT-PCR of RNA extracted by conjunctival epithelial cells obtained by cytology impression. The real time PCR measurement demonstrated a correlation among mRNA expression and tear AMCase activity (Figure 4).

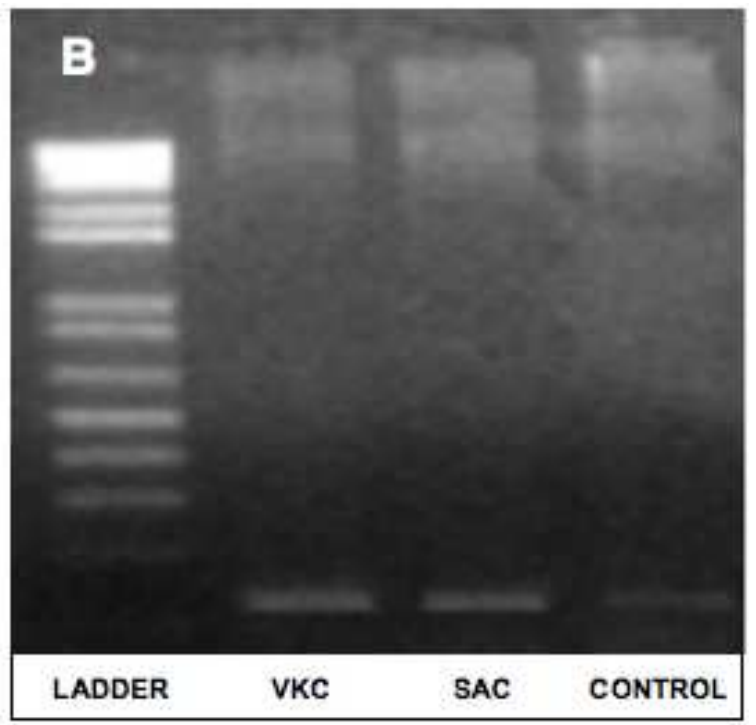

Figure 4. (A) Detection of AMCase expression by quantitative real time PCR of RNA obtained from 8 Controls, 6 Vernal conjunctivitis (VKC), and 7 Season conjunctivitis (SC) patients. (B) Two percent Agarose Gel with AMCase PCR products of one patient with VKC, SAC and control respectively. Note the lower intensity of the amplicon band in Control, showing a generally decreased expression of AMCase mRNA as compared with VKC and SAC (from Musumeci et al 2008).

\section{Experimental Uveitis}

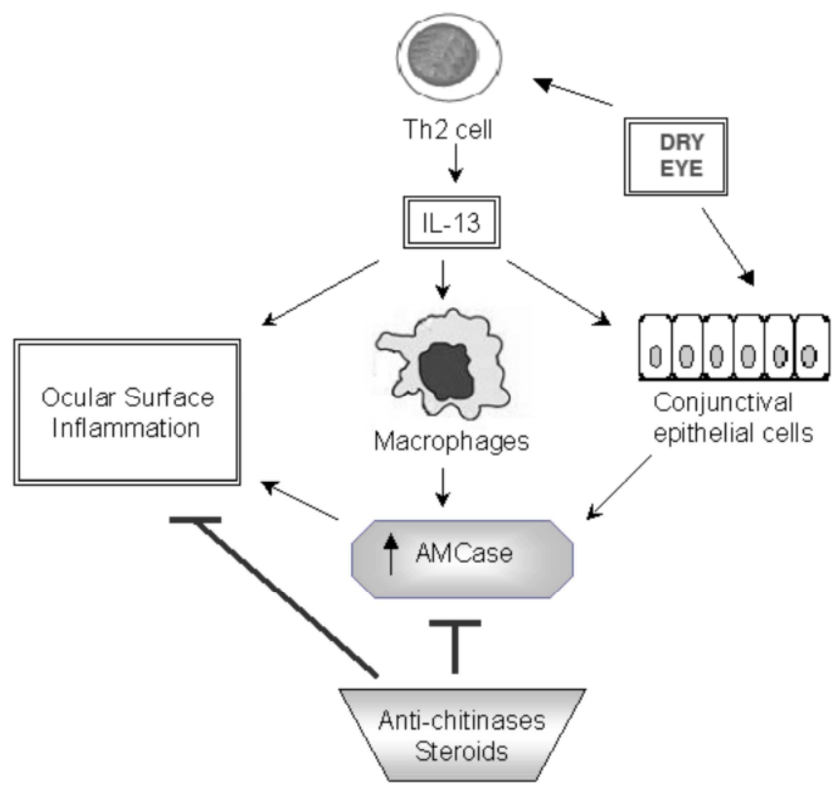

Figure 5. Hypothetical model of AMCase and IL-13 control of Th2-driven ocular surface inflammation in rabbit endotoxin induced uveitis (EIU): effect of chitinase inhibitors and steroids (From Bucolo et al 2008).

A recent study in rabbit, where an experimental uveitis was induced injecting LPS in anterior chamber of eye, confirmed that the chitinolitic activity in tears collected at different time $0,6,24 \mathrm{~h}$ after injection, was due to AMCase
[15]. In fact uveitis makes up a group of heterogeneous diseases characterized by an intraocular inflammatory process that involves many complex immune pathways still not completely determined. It seems that Th1 system dominates intraocular inflammation, and that on the ocular surface Th2 immune responses may also be present [16]. In fact in both uveitis and VKC, a CC chemokine receptor 4 (CCR4) related to the Th2 system was found significantly increased [16]. According to this observation an hypothetical model of AMCase and IL-13 control of Th2 driven ocular surface inflammation has been proposed in Figure 5.

Similarly to that found in asthma model of Zhu et al [7], the inflammatory reaction induced by LPS was controlled by instillation of chitinase inhibitors such as allosamidin and/or caffeine and dexamethasone.

Tear AMCase activity in rabbit treated with allosamidin, caffeine, dexamethasone and PBS has been measured and expressed as nmol $/ \mathrm{ml} / \mathrm{h}$. Figure 6 shows the kinetics of AMCase activity in tears of rabbit treated with PBS before and after LPS injection. Before the induction of EIU with LPS injection the AMCase activity (basal) was very low $(22.82+1.07 \mathrm{mmol} / \mathrm{ml} / \mathrm{hr})$ in the tears. LPS injection caused a significant increase of AMCase activity, which reached the maximum at $6 \mathrm{~h}$ and $24 \mathrm{~h}(324.50+30.0$ and $328.40+26.00$ $\mathrm{mmol} / \mathrm{ml} / \mathrm{hr}$ respectively) (see Figure 6).

The chitinolytic activity was not reduced decreasing the mixture reaction at $\mathrm{pH} 2$ in the samples obtained at 6 and 24 $\mathrm{h}$, confirming that this activity was characteristic of AMCase. 


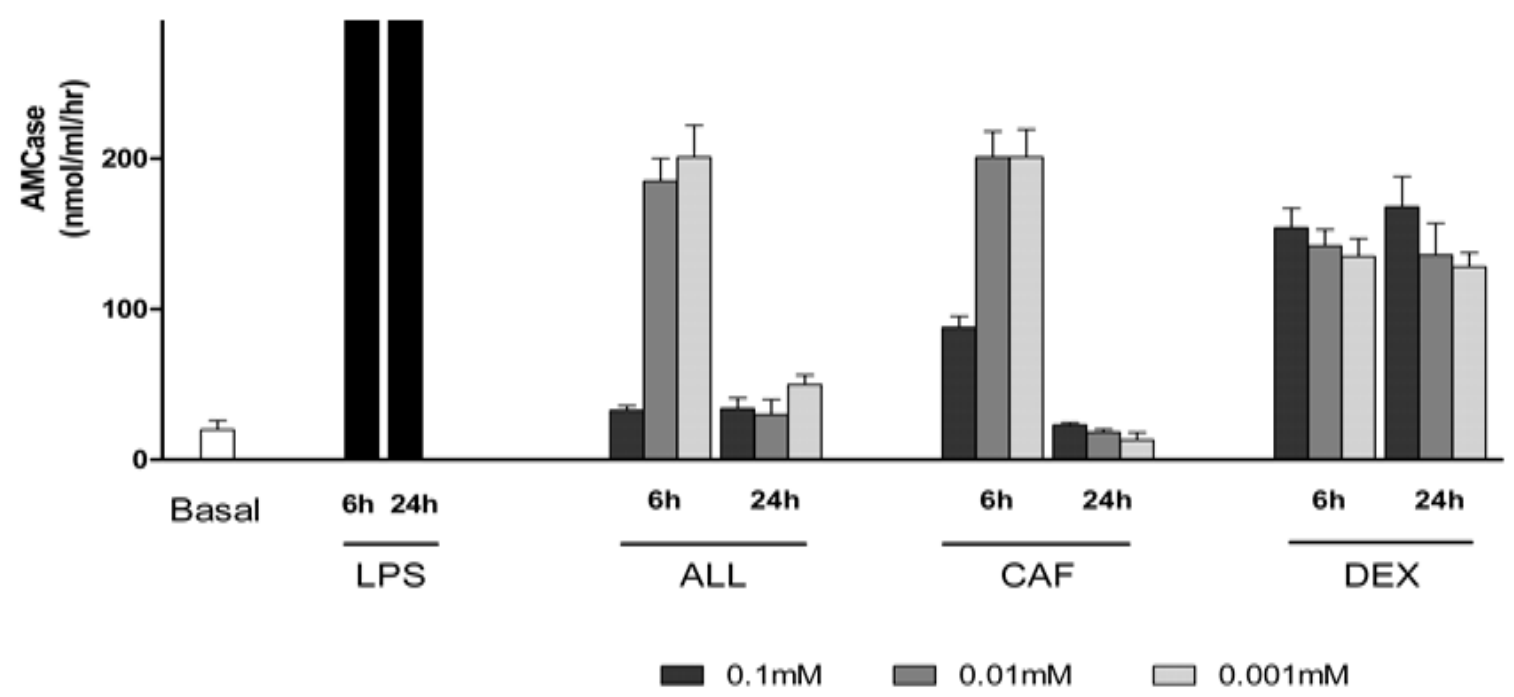

Figure 6. AMCase activity ( $m U / m g$ tear protein) before (basal) and at $6 \mathrm{~h}$ and $24 \mathrm{~h}$ after LPS intravitreal injection, at 6 and $24 \mathrm{~h}$ after conjunctival instillation of different concentration $0.1 \mathrm{mM}, 0.01 \mathrm{mM}$ and $0.001 \mathrm{mM}$ of allosamidin (ALL), caffeine (CAF) and Dexamethasone (DEX) (From Bucolo et al 2008).

A significantly dose-related inhibition of AMCase activity has been observed at $6 \mathrm{~h}$ and $24 \mathrm{~h}$, in allosamidin-treated group as well as in caffeine-treated group compared to the LPS group $(P<0.0001)$. Likewise, the group treated with dexamethasone showed a significant inhibition of AMCase activity that was not dose-dependent both at $6 \mathrm{~h}$ and $24 \mathrm{~h}(\mathrm{P}$ $<0.0001)$. A statistical difference in terms of AMCase activity (Figure 6) between allosamidin and caffeine $(33.00+$ 5.21 and $88.00+7.30 \mathrm{mmol} / \mathrm{ml} / \mathrm{hr}$ respectively, $\mathrm{P}<0.0001$ ), has been observed at $6 \mathrm{~h}$ with the highest concentration $(0.1 \mathrm{mM})$, but this difference was not significant with 0.01 and $0.001 \mathrm{mM}$ concentrations. With the concentration of $0.0001 \mathrm{mM}$ the effect on the AMCase activity was comparable to that observed with PBS and no significant differences were observed at $24 \mathrm{~h}$ among $0.0001 \mathrm{mM}$ concentration in all responder treated groups (data not shown). The clinical evaluation of the drug treatments is summarized in figure 7 .

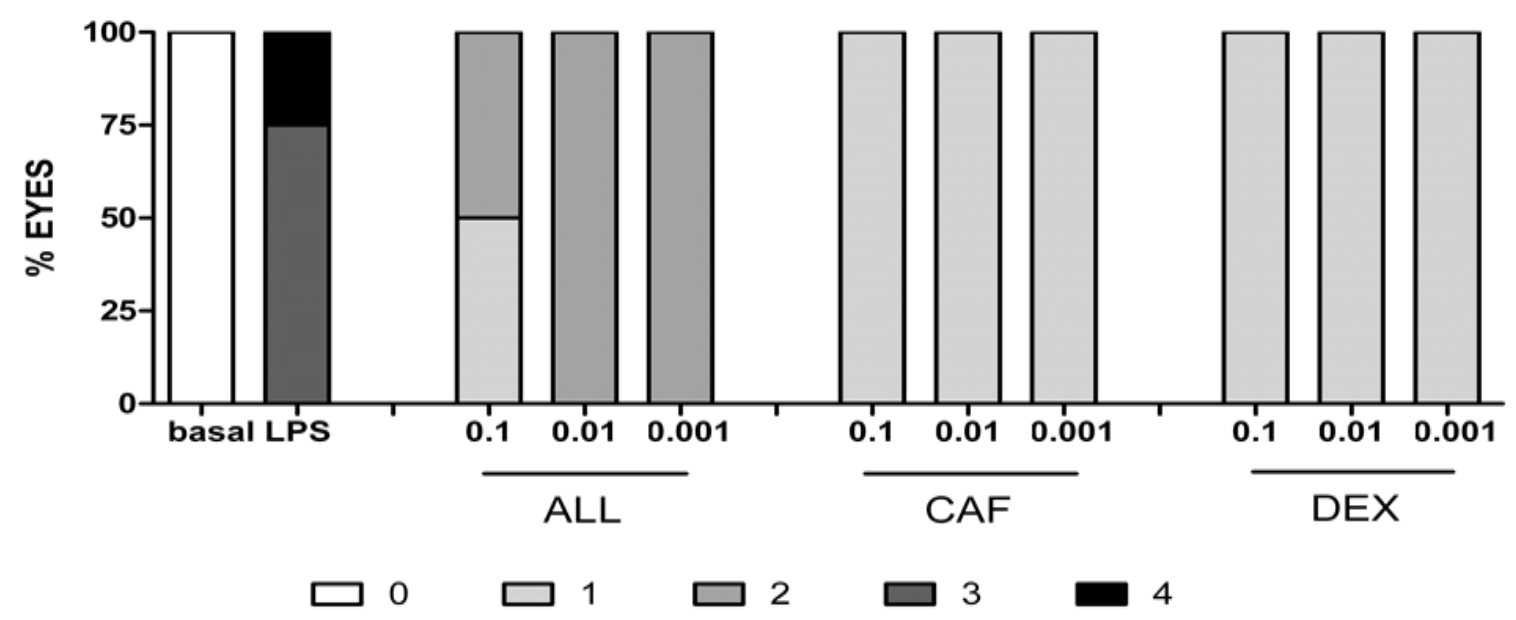

Figure 7. Clinical evaluation 24 h after EIU induction. Grading criteria: $0=$ normal; 1 = discrete dilatation of iris and conjunctival vessels; 2 = moderate dilatation of iris and conjunctival vessels; $3=$ intense iridal hyperemia with flare in the anterior chamber; $4=$ intense iridal hyperemia with flare in the anterior chamber and presence of fibrinous exudates. ${ }^{*} p<0.001$ vs LPS and **p<0.01 vs $0.01 \mathrm{mM}$ and $0.001 \mathrm{mM}$ ALL by Dunn test after Kruskal-Wallis (From Bucolo et al, 2008).

Absence of inflammation (score 0) was observed in all groups before LPS injection, on the contrary a severe inflammatory response (clinical score $=3-4$ ) was found at $6 \mathrm{~h}$ and $24 \mathrm{~h}$ after EIU induction. Topical instillation of allosamidin or caffeine, caused a remarkable reduction of ocular inflammation (clinical score $=2$ and 1 for allosamidin and caffeine respectively) at all doses tested, except at the lowest $(0.0001 \mathrm{mM})$ concentration. Also the group treated with dexamethasone showed an important decrease of ocular inflammation at all responder doses with a clinical score of 1 . Further, the clinical effect with $0.0001 \mathrm{mM}$ dexamethasone was not different from the group treated with PBS, where the score remained about 3-4 (data not shown). In our previous work we demonstrated that the drugs used in this study, when 
instilled alone, did not affect the tear AMCase activity, further they did not show any ocular irritation. In this study caffeine was used because binds to the active site of chitinase in the same way of the well-known chitinase inhibitor allosamidin [17], but surprisingly, among its multiple mechanism of action, i.e. adenosine receptor antagonist, phosphodiesterase inhibitor, histone deacetylase inducer, caffeine can acts via chitinase inhibition, and this mechanism over the others is probably associated to anti-inflammatory effect [18]. The chitinase represents also a target for glucocorticoids, in fact recently Zhao et al [19] demonstrated that in mice sensitized and challenged with ovalbumin (OVA), dexamethasone downregulated acidic mammalian chitinase (AMCase) in the bronchial tissue. Similarly dexametasone inhibit the AMCase expression in conjunctival epithelial cells in rabbit uveitis, where a significant reduction of AMCase activity was observed in the tears of rabbit with uveitis treated with the glucocorticoid. The source of AMCase from the conjunctival epithelial cells is sustained from the direct evidence in our previous study of a correlation among AMCase activity and expression of mRNA by conjunctival epithelial cells of SAC and VKC patients, obtained by impression cytology [14]. In addition the inhibition of ocular inflammation in the group treated with dexamethasone was significantly higher compared to the group treated with allosamidin, probably because corticosteroids act through multiple mechanisms [1819]. Interestingly, a similar effect was observed with caffeine that determined a significant inhibition of AMCase and a robust attenuation of clinical score. Also in this case the reason is likely due to the several mechanisms of action of this methylxanthine [18].

The exact function of AMCase in the conjunctival tissue is still object of speculations. The only consistent data come again from Ramanathan et al [10], who demonstrated by real time PCR the presence of specific mRNA in the tissue of recurrent nasal polyps and from our data in SAC and VKC, where AMCase mRNA was over-expressed by epithelial cells of conjuntival tissue and the magnitude of this expression was correlated with the clinical severity of the diseases. [14].

Since chitin is not naturally present in mammals, the abnormal production of corresponding enzyme (i.e. AMCAse) in allergy and inflammatory diseases, and its role in the build up of mucus and other fluid or in the polyp formation in human chronic sinusitis open the way to legitimate this enzyme as a target for drug therapies to block its action or where possible its production. This consideration seems to be in contrast to the observation of Reese et al [20], who demonstrated that the inoculation of chitin in mice determine a recruitment of inflammatory cells (eosinophils and basophils), characteristic of allergic response and that the inoculation with chitin of AMCase precluded this effect, raising the possibility that inherent deficits in human chitin degradation could underlie airway inflammation and favour allergic reaction. However, as Reese et al [20], correctly acknowledge, other studies suggest that chitin has a rather relevant role in immune response. Oral administration of chitin, for instance, has been shown to down modulate a murine model of allergic airway inflammation [21]. Another study by Strong et al [22] demonstrated that direct application of chitin microparticles to the respiratory tract can alleviate allergic symptoms in a mouse model of allergy. In both studies, the importance of the route of administration (oral and nasal, respectively) seems to be a key point for the ability of chitin to induce a Th1 anti-allergic effect and confirm the Th 2-specific, IL-13 mechanism proposed in this chapter (see Figure 1).

In addition the size of the chitin particles that people are exposed may result in different effects on biology and may expose some of the mystery of chitin and chitinases binomium. For example, depending on the size of chitin particles, these may or may not be phagocytized and displayed by dendritic cells to T-cells to stimulate a immune response. The size or polymerization of chitin could affect the chemo attractive potential of the molecule.

Nonetheless, our previous results in humans regarding ocular allergies and the data generated from the present study on experimental uveitis are very intriguing. We believe that all hypotheses generated at this point in the field are plausible and interesting to pursue [23]. In fact, both hypotheses regarding AMCase's role in immuno inflammatory conditions may be true at the same time, taking into account that the site of inflammatory process as well as the administration route of the pharmacological tools are of primary importance. Chitin preparation used in murine model of allergy could mimic the effect of inhibitors of chitinase because of the high affinity with AMCase and support our observation in the rabbit model of EIU.

In this study we do not measured the level of IL-13, because kits for the measurement of IL-13 in rabbit were not available, but data reported by Zhu et al [24] support the correlation between AMCase expression in bronchial tissue and increase of IL-13 as a marker of Th2 response typical of allergic diseases with a sequential mechanism (Figure 2). Also in this study the inhibition of AMCase activity with the chitinase inhibitor, allosamidin and caffeine, determined in rabbits, injected by LPS, a decrease of inflammatory response as well as in the mice that over expressed IL-13 the inhibition of AMCase with allosamidin decreases also the inflammation suggesting a modulation effect of AMCase in the airways hyper-responsiveness [24].

This results open the way to the role of chitinases in the mechanism of allergic eye inflammation or to consider inhibitor as a target for new innovative treatment hypothesis.

\section{Dry Eye Syndrome}

Other non allergic ocular inflammation may be associated to AMCAse secretion in tears and to conjunctival cells expression. Since the chitinase belong to the innate immunity, the dry eye due of alteration to lacrimal film with different mechanism could be associated to AMCase expression in human eye.

In fact dry eye is an ocular disease determined by a reduced tear film stability that can be characterized by a decreased 
aqueous component production or by an increased evaporation. This condition is accompanied by ocular discomfort symptoms such as burning, foreign body sensation, impaired vision and may interfere with patients' quality of life [25]. Epidemiological studies have estimated that it affects between the 11 and $17 \%$ of the general population, with an increasing prevalence in older people [26-27]; this number increases with the aging populations, resulting in a significant decrease in the quality of life and it was found that, among people asking for ophthalmologic referral, the $29 \%$ has a dry eye [28-29]. Dry eye is caused by an impaired function of the tear film that lubricates the ocular surface. Tear film is a complex structure where two main layers are recognizable: a thin lipid layer, directly exposed to the environment, and an underlying mucous-aqueous layer which is the main part of the structure and is in contact with the epithelium.

Dry eye is caused when the tears produced by the eyes are insufficient to moisture, and lubricate the ocular surface. Environmental factors can also play a role in its pathogenesis [30]. Examples include dusty air, hot-dry or windy climate, or fumes like cigarette smoke which can evaporate tears much speedily or hamper their effectiveness [31]. Contact lens wear may also induce dry eye as the lens materials tend to absorb water and protein from the tear film and because a long term contact lens use reduces corneal sensitivity and lacrimal secretion [32].

People who watch TV, use a laptop, or read for a longer duration may cause eye strain due to dry eye. This is due to straining of the eyes, reduced blinking and is often accompanied by altered meibomian gland secretion [33-34] Inadequate sleep or insomnia can also cause dry eyes, as the ocular surface is overexposed and is apt to dry up faster. Finally, dry eyes are a frequent side effect of many systemic and topical drugs and medical conditions, such as Thyroid diseases, Parkinson's Disease, Sjögren's Syndrome (SS), and deficiency in vitamin A [35]. Most women experience dry eyes as they enter menopause, due to the changes of the hormonal status [30-36].

Ocular discomfort and visual impairment are the possible consequence of the dry eye condition [29] and the for dry eye treatment is the use of artificial tears, which is often accompanied by the use of anti-inflammatory eye drops. such as a corticosteroid and/or cyclosporine $\mathrm{A}$ [37].

Recently several reports associate the dry eye to an inflammatory condition of the ocular surface. Increased endogenous ICAM-1 expression and production was detected in conjunctival epithelial cells and accessory lacrimal tissues of dry eye patients. ICAM-1, synthesized by epithelial cells, may serve as a signaling molecule for the predisposition to ocular surface inflammation and facilitate the presentation of potential antigen by epithelial cells [38]. This can be a clue to understand the pathogenetic mechanisms underlying the association among the dry eye manifestations and allergic ocular diseases [39].

Moreover experimental dry eye in mouse stimulates expression and production of IL-1 alpha, IL-6, TNF-alpha, and MMP-9 and activates MAPK signaling pathways on the ocular surface, which could play an important role in the induction of those inflammatory mechanisms implicated in the pathogenesis of dry eye [40-41]

There are different response in $\mathrm{C} 57 \mathrm{BL} / 6$ mice, where desiccating stress significantly increased the concentrations of MIP-1alpha, MIP-1beta, IP-10, and MIG proteins in the corneal epithelium and conjunctiva, while in $\mathrm{BALB} / \mathrm{c}$ mice the levels of MCP-3, eotaxin-1, and CCR3 transcripts increased in ocular tissues [41]. These two different responses demonstrate that some desiccating stress can induce specific patterns of Th1 and Th- 2 chemokines and their receptors in a strain-related fashion. In fact the expression of Th-1 interleukin (IL)-1alpha, IL-6, and tumor necrosis factor (TNF)-alpha transcripts were higher in the corneal epithelium and conjunctiva of $\mathrm{C} 57 \mathrm{BL} / 6$ mice and Th-2 cytokines IL-4 and IL-10 were significantly greater in BALB/c tears [41]. The information obtained in the dry eye mouse model could be translated to human, where the continuous physical trauma induced by alteration of tear composition, activate an inflammation with the same mediator characteristic of Th-1 and Th-2 immune response [42].

If studies encourage further understanding of the intricate interactions of Th1 and Th2 cytokines in dry eye syndrome, the role of innate immunity was never considered sufficiently.

The epithelial cells lining nasal and conjunctival surfaces could play an important role as first responders of the immune system. They are capable of actively participating in immune reactions via expression of surface antigens, such as adhesion molecules, and synthesis of cytokines. This appears to be important in the pathophysiology of non-ocular allergic disorders [43]. Among other factors, it was shown that they can produce chitinases [14]. In fact it was demonstrated that the AMCase activity and the mRNA expression in the epithelial conjunctical cells of vernal keratoconjunctivitis (VKC) and season allergic conjunctivitis (SAC) was increased, introducing a new diagnostic and therapeutic marker in the pathogenesis of allergic conjunctivitis.

In patients with meibomia gland disfunction (MGD) dry eyes and with secondary to Sjogren's (SS) dry eye and in healthy subjects (all adults) we collected tears to measure AMCase activity and conjunctival epithelial cells to measure AMCase expression.

AMCase activity was significantly higher in the group of MGD dry eyes compared to SS dry eye $(\mathrm{p}<0.0001)$, while in the healthy controls the AMCase was very low (data not shown). Real-time PCR analysis showed a consistent up regulation of AMCase in the MGD dry eye patients with respect to SS dry eye and normal controls (Figure 8), providing data on its cellular origin. The quantitative real time evaluation of AMCase indicated a strongly increase in MGD dry eye compared to control whereas in SS dry eye the increase is minor. In VKC the levels of AMCase activity were high and these activities were reduced to normal values when the patients were treated locally with steroids. The difference among the concentration of AMCase mRNA were statistically different with a $\mathrm{p}<0.0001$ comparable to that found analysing the AMCase activity. In the SS dry eye the pathogenetic mechanism is linked to a immune process 
which involve the ocular surface with a marked reduction of the aqueous phase of tears as a hallmark of the disease (aqueous deficient dry eye). In the MGD form the pathogenetic mechanisms is different (evaporative dry eye): altered tear film is characterized by a primary alteration of the lipid component which can be accompanied by a modified bacterial flora on the conjunctiva [44-45]. This might induce a stronger innate response as demonstrated by the higher AMCase expression level.
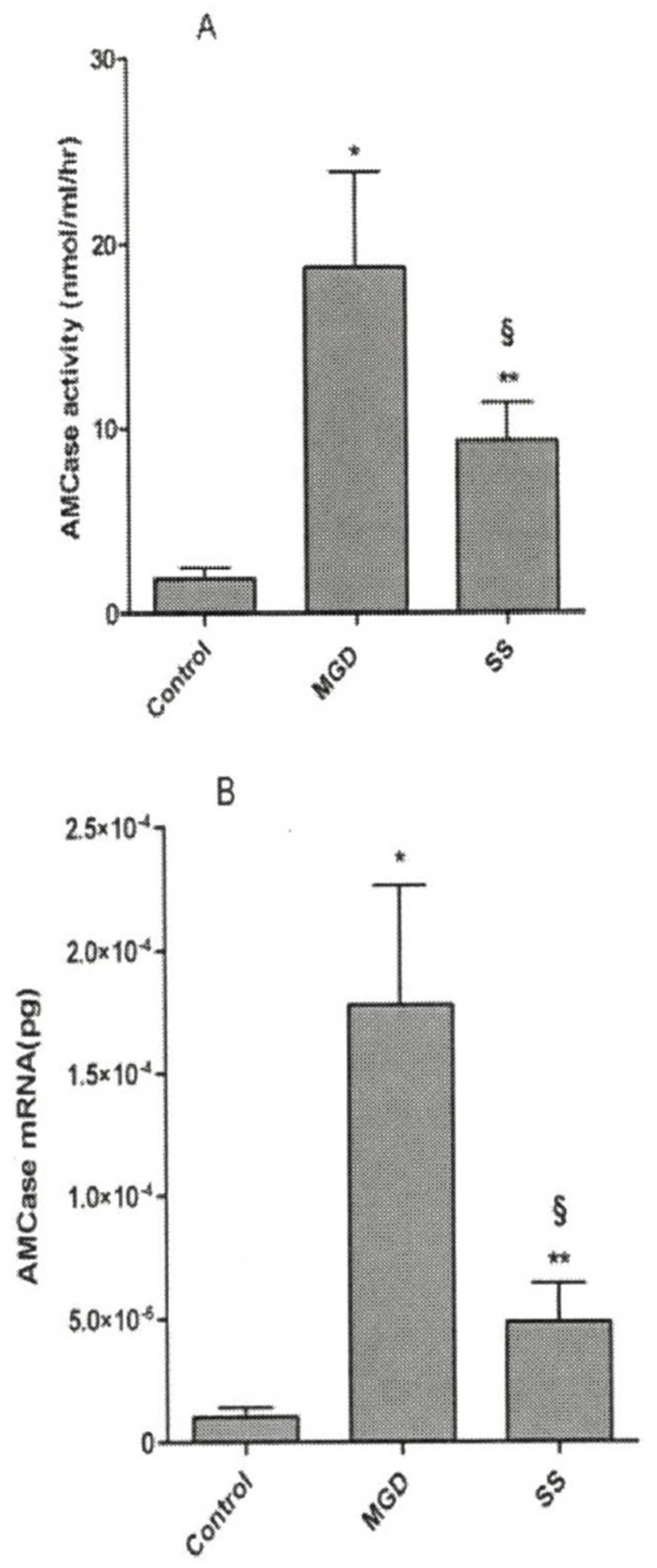

Figure 8. Reported the levels of AMCase activity and the quantity (pg) of mRNA in patients with MGD dry eyes, SS dry eye and healthy controls. In addition are reported the level of AMCase $m R N A$ in a VKC patients before and after therapy with topical steroids.
The results support the hypothesis that similar mechanism associate the allergic ocular pathologies to dry eye.

The final consideration on the role of AMCAse in the ocular allergic and not allergic pathologies seem now supported by biochemical and molecular evidences.

Our preliminary results confirm that the instillation of chitinase inhibitor in conjunctival sac both in rabbit model and in human allergic conjunctivitis and in dry eye syndromes reduce the clinical symptoms. Both inhibitor and steroids interrupt the pathogenetic mechanism inhibiting the enzymatic activity or blocking the molecular espression of AMCase.

The steroid and cyclosporine A use in dry eye and in VKC and SAC find their rationale in the new role of the AMCase in the pathogenesis of ocular inflammation, but the role of chitinase in the physiopathology of eye is not completely understood.

In fact another chitinase, chitotriosidase, has been shown to be expressed in connection with lysozyme in human lacrimal gland [46]. This chitinase produced by macrophage and neutrophils point to a role in the innate immunity [47]. Since this chitinase was considered more active in the control of chitin containing pathogens, the presence of measurable chitotriosidase activity in human tears seem to support the eye protection in both human and mouse [48]. In this contest it is interesting to note that chitotriosidase unlike bacterial chitinases do not appear to have any mucolytic activity [49] so the lacrimal film is not modified in its structure, maintaining the integrity of visual function.

The trigger function of innate immunity, conditioning the more complex adaptative immunity, deserves other study in pathologies, where the tissue inflammation is responsible of clinical manifestations.

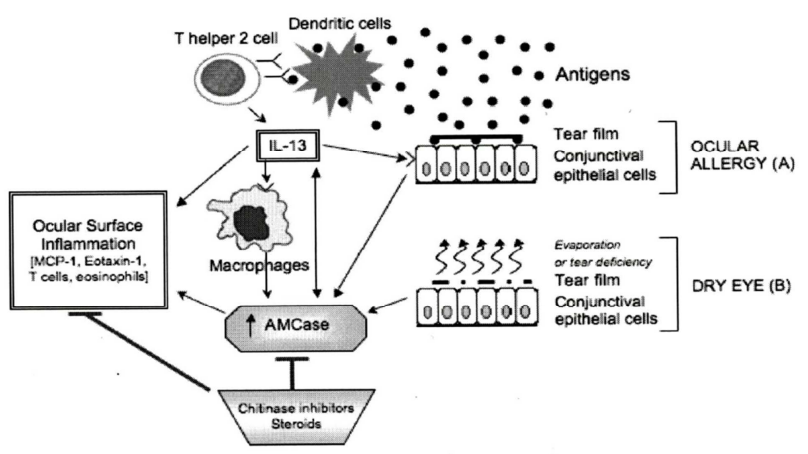

Figure 9. Model of AMCase-mediated ocular allergy and dry eye inflammation: (A) dendritic cells actively uptake antigens (chitin?) and present this antigen to Th2 cell producing $I L-13$, which play a role to induce AMCase by conjunctival cells and macrophages, both expressing receptor (IL-13R) on their surface. Of note, AMCase stimulates MCP-1 and eotaxin-1 production, which induce the recruitment of $T$ cells, eosinophils and macrophages, sustaining ocular surface inflammation; (B) alteration of tear film (e.g. excessive evaporation or tear deficiency) stimulates conjunctival cells to AMCase expression which induces ocular surface inflammation with the same mechanism. Chitinase inhibitors may suppress ocular surface inflammation blocking the AMCase enzymatic activity, while steroids inhibit its expression (From Musumeci et al 2008). 


\section{References}

[1] Debono M, Gordee RS. Antibiotics that inhibit fungal cell wall development. Annu. Rev. Microbiol. 1994; 48:471-97.

[2] Neville AC, Parry DA, Woodhead-Galloway J. The chitin crystallite in arthropod cuticle. J Cell Sci. 1976; 21:73-82.

[3] Araujo AC, Souto-Padron T, de Souza W. Cytochemical localization of carbohydrate residues in microfilariae of Wuchereria bancrofti and Brugia malayi. J. Histochem. Cytochem. 1993;41:571-78.

[4] Kawada M, Hachiya Y, Arihiro A, Mizoguchi E. Role of mammalian chitinases in inflammatory conditions. Keio $\mathrm{J}$ Med. 2007; 56(1):21-7.

[5] Boot RG, Blommarart EF, Swart E et al. Identification of a novel acidic mammalian chitinase distinct from chitotriosidase, J Biol Chem. 2001; 276: 6770.78.

[6] Chou YT, Yao S, Czerwinski R, Fleming M, Krykbaev R, Xuan D, Zhou H, Brooks J, Fitz L, Strand J, Presman E, Lin L, Aulabaugh A, Huang X.Kinetic characterization of recombinant human acidic mammalian chitinase. Biochemistry. 2006 Apr 11;45(14):4444-54.

[7] Zhu Z, Zheng T, Homer RJ et al. Acidic mammalian chitinase in asthmatic Th2 inflammation and IL-13 pathway activation. Science. 2004;304:1678-82.

[8] Donnelly LE, Barnes PJ. Acidic mammalian chitinase - a potential target for asthma theraphy. Trends Pharmacol. Sci. 2004; 25: 509-11.

[9] Sakuda S, Isogai A, Matsumoto S, Suzuki A. Search for microbial insect growth regulators. II. Allosamidin, a novel Insect chitinase inhibitor. J Antibiot (Tokyo). 1987; 40: 296300 .

[10] Ramanathan MJ, Lee WK, Lane AP. Increased expression of acidic mammalian chitinase in chronic rhinosinusitis with nasal polyps. Am. J. Rhinol. 2006; 20: 330-35.

[11] Chupp GL, Lee CG, Jarjour N, Shim YM, Holm CT, He S, Dziura JD, Reed J, Coyle AJ, Kiener P, Cullen M, Grandsaigne M, Dombret MC, Aubier M, Pretolani M, Elias JA. A chitinaselike protein in the lung and circulation of patients with severe asthma. N Engl J Med. 2007; 357: 2016-27.

[12] Ono SJ. Vernal keratocojunctivitis: evidence for immunoglobulin E-dependent and immunoglobulin Eindependent eosinophilia. Clin. Exp. Allergy. 2003; 33: 279-81

[13] Metz DP, Hingorani M, Calder VL, Buckley RJ, Lightman SL. T-cell cytokines in chronic allergic eye disease J. Allergy Clin. Immunol. 1997; 100: 817-24.

[14] Musumeci M, Maltese A, Bucolo C, Musumeci S. Chitinase levels in the tears of subjects with ocular allergies. Cornea 2008; 27: 168-73.

[15] Bucolo C, Musumeci M, Maltese A, Drago F, Musumeci S. Effect of chitinase inhibitors on endotoxin-induced uveitis in rabbits. Pharmacology Research 2008 in press.

[16] Trinh L, Brignole-Baudouin F, Raphaël M, Dupont-Monod S, Cassoux N, Lehoang P, Baudouin C. Th1 and Th2 responses on the ocular surface in uveitis identified by CCR4 and CCR5 conjunctival expression. Am J Ophthalmol. 2007; 144: 580-5.
[17] Rao FV, Andersen OA, Vora KA, Demartino JA, van Aalten DM. Methylxanthine drugs are chitinase inhibitors: investigation of inhibition and binding modes. Chem Biol. 2005; 12: 973-80.

[18] Undem BJ. Pharmacotheraphy of asthma. In: Brunton LL, Lazo JS, Parker KL, eds. Goodman \& Gilman's The pharmacological basis of therapeutics. 11th ed. McGraw-Hill, 2006: 717-36.

[19] Zhao J, Yeong LH, Wong WS. Dexamethasone alters bronchoalveolar lavage fluid proteome in a mouse asthma model. Int Arch Allergy Immunol. 2007; 142: 219-29.

[20] Reese TA, Liang HE, Tager AM, Luster AD, Van Rooijen N, Voehringer D, Locksley RM. Chitin induces accumulation in tissue of innate immune cells associated with allergy. Nature. 2007; 447: 92-6.

[21] Shibata Y, Foster LA, Bradfield JF, Myrvik QN. Oral administration of chitin down-regulates serum IgE levels and lung eosinophilia in the allergic mouse. J Immunol. 2000; 164: 1314-21.

[22] Strong P, Clark H, Reid K. Intranasal application of chitin microparticles down-regulates symptoms of allergic hypersensitivity to Dermatophagoides pteronyssinus and Aspergillus fumigatus in murine models of allergy. Clin Exp Allergy. 2002; 32: 1794-800.

[23] Burton OT, Zaccone P. The potential role of chitin in allergic reactions. Trends Immunol. 2007; 28: 419-22.

[24] Zhu Z, Ma B, Zheng T, Homer RJ, Lee CG, Charo IF, Noble P, Elias JA. IL-13-induced chemokine responses in the lung: role of CCR2 in the pathogenesis of IL-13-induced inflammation and remodeling. J Immunol 2002; 168: 2953-62.

[25] The definition and classification of dry eye diseases: report of the definition and classification subcommittee of the International Dry Eye WorkShop Ocul Surf 2007; 5(2):75-92.

[26] Moss SE, lein R, Klein BE. Prevalence and risk factors for dry eye syndrome. Arch Ophthalmol 2000; 118:1264-8.

[27] Lee AJ, Lee J, Saw SM, Gazzard G, Koh D, Widjaja D, Tan DT. Prevalence and risk factors associated with dry eye symptoms: a population based study in Indonesia. Br J Ophthalmol 2002; $86: 1347-51$

[28] Moss SE, Klein R, Klein BE. Incidence of dry eye in an older population. Arch Ophthalmol 2004; 122:369-73.

[29] Miljanovic B, Dana R, Sullivan DA, Schaumberg DA. Impact of dry eye syndrome on vision-related quality of life. Am J Ophthalmol 2007; 143:409-15.

[30] Stern ME, Beuerman RW, Fox RI, Gao J, Mircheff AK, Pflugelder SC. The pathology of dry eye: The interaction between the ocular surface and lacrimal glands. Cornea 1998; 17(6):584-589.

[31] Altinors DD, Akça S, Akova YA, Bilezikçi B, Goto E, Dogru M, Tsubota K. Smoking associated with damage to the lipid layer of the ocular surface. Am J Ophthalmol. 2006; 141(6):1016-1021.

[32] Epstein AB. Contact lens care products effect on corneal sensitivity and patient comfort. Eye Contact Lens. 2006; 32(3):128-32.

[33] Bergqvist UO, Knave BG. Eye discomfort and work with visual display terminals. Scand J Work Environ Health 1994; 20:2733. 
[34] Fenga C, Aragona P, Cacciola A, Spinella R, Di Nola C, Ferreri F, Rania L. Meibomian gland dysfunction and ocular discomfort in video display terminal workers. Eye. 2007 Oct 26 .

[35] O'Day DM, Horn JD. The Eye and Rheumatic Disease. In: Kelley WN editor. Textbook of Rheumatology, 6th ed. Philadelphia: Saunders, 2001: chapter 29.

[36] Versura P, Campos EC. Menopause and dry eye. A possible relationship. Gynecol Endocrinol. 2005; 20(5):289-98.

[37] Willen CM, McGwin G, Liu B, Owsley C, Rosenstiel C. Efficacy of Cyclosporine $0.05 \%$ Ophthalmic Emulsion in Contact Lens Wearers With Dry Eyes. Eye Contact Lens. 2008; 34(1):43-45.

[38] Narayanan S, Miller WL, McDermott AM. Conjunctival cytokine expression in symptomatic moderate dry eye subjects. Invest Ophthalmol Vis Sci. 2006; 47(6):2445-50.

[39] Stern ME, Siemasko KF, Gao J, Calonge M, Niederkorn JY, Pflugfelder SC. Evaluation of ocular surface inflammation in the presence of dry eye and allergic conjunctival disease. Ocul Surf. 2005; 3 (4 Suppl):S161-4.

[40] Pflugfelder SC, Jones D, Ji Z, Afonso A, Monroy D. Altered cytokine balance in the tear fluid and conjunctiva of patients with Sjögren's syndrome keratoconjunctivitis sicca. Curr Eye Res. 1999; 19(3):201-11.

[41] Corrales RM, Villarreal A, Farley W, Stern ME, Li DQ, Pflugfelder SC. Strain-related cytokine profiles on the murine ocular surface in response to desiccating stress. Cornea. 2007; 26(5):579-84.
[42] Stern ME, Siemasko KF, Niederkorn JY. The Th1/Th2 paradigm in ocular allergy. Curr Opin Allergy Clin Immunol. 2005; 5(5):446-50.

[43] Hingorani M, Calder VL, Buckley RJ, Light man SL. The role of conjunctival epithelial cells in chronic ocular allergic disease. Exp Eye Res. 1998; 67(5):491-500.

[44] Mahajan VM. Acute bacterial infections of the eye: their aetiology and treatment. Br J Ophthalmol. 1983; 67(3):191-4.

[45] Seal DV, Barrett SP, McGill JI. Aetiology and treatment of acute bacterial infection of the external eye. Br J Ophthalmol. 1982; 66(6):357-60.

[46] Hall AJ, Morroll S, Tighe P, Götz F, Falcone FH. Human chitotriosidase is expressed in the eye and lacrimal gland and has an antimicrobial spectrum different from lysozyme. Microbes Infect. 2007 Oct 22; doi: 10. 1016/j. micinf. 2007. 10. 007.

[47] Van Eijk M, van Roomen CP, Renkema GH, Bussink AP, Andrews L, Blommaart EF, Sugar A, Verhoeven AJ, Boot RG, Aerts JM. Characterization of human phagocyte-derived chitotriosidase, a component of innate immunity. Int Immunol. 2005; 17(11):1505-12.

[48] Gianfrancesco F, Musumeci S. The evolutionary conservation of the human chitotriosidase gene in rodents and primates. Cytogenet Genome Res. 2004; 105(1):54-6.

[49] Sanders NN, Eijsink VG, van den Pangaart PS, Joost van Neerven RJ, Simons PJ, De Smedt SC, Demeester J. Mucolytic activity of bacterial and human chitinases. Biochim Biophys Acta. 2007; 1770(5):839-46. 